\title{
Titel/Title: The Autonomy of Modern Sport: Dangerous and Endangered
}

Autor*innen/Author(s): Uwe Schimank

Veröffentlichungsversion/Published version: Postprint

Zeitschriftenartikel/Journal article

\section{Empfohlene Zitierung/Recommended citation:}

Schimank, Uwe (2005): The Autonomy of Modern Sport: Dangerous and Endangered. In: European Journal of Sport and Society, 2 (1), 13-23.

Verfügbar unter/Available at:

(wenn vorhanden, bitte den DOI angeben/please provide the DOI if available)

This is an Accepted Manuscript of an article published by Taylor \& Francis in European Journal of Sport and Society on 31.03.2016, available online:

https://doi.org/10.1080/16138171.2005.11687762

Zusätzliche Informationen/Additional information:

The author can be contacted at: uwe.schimank@uni-bremen.de 
Uwe Schimank

The Autonomy of Modern Sport: Dangerous and Endangered

Autonomy is one of the central values in modern society. One might even say that it is the most important value for the self-understanding of modernity. On the level of persons, the modern individual is unthinkable without its autonomy, often expressed as its freedom to act according to its own will. On the level of societal subsystems, autonomy is understood as the right - often legally codified - of non-interference of external forces into their "core technology" (Thompson 1967), as we might call the operations which constitute a subsystem's peculiar logic. Thus, we proclaim the "freedom of science" or the "independence of the law", to give just two familiar examples.

Sport is one of the subsystems of modern society; and just as the law or science or the economy it proclaims its autonomy. Of course, as for individuals, such proclamations are not made out of the blue. Autonomy is usually a latent property of individuals or societal subsystems. When it is talked about, most of the time there is something wrong with it. As we all know, for decades now representatives of the sport system, and politicians responsible for sport policy often refer explicitly to the autonomy of sport, in general $(\leftarrow$ p. 1) statements as well as in specific issues. Thus, we may suspect that there are some ongoing problems with this subsystem's autonomy.

This is my topic now; and I shall deal with it by distinguishing further the two second-order subsystems of sport: top athletics, on the one hand, and leisure sport, on the other. My conclusion will be that both subsystems of modern sport indeed have autonomy trouble, but of a quite different nature. I will start with a brief exposition of my theoretical perspective, and then discuss top athletics and leisure sport, one after the other. After that, I will conclude by turning to the relation between these two subsystems of the sport system with respect to their different autonomy problems. 
From the point of view of sociological theories of societal differentiation, which I adopt here (Schimank 1996; 2002), modern sport is one differentiated subsystem of modern society among about a dozen others. In this view, modern society is characterised by its functional differentiation. By Emile Durkheim and Talcott Parsons this is understood as a fruitful division of labour among societal subsystems, analogous to the division of labour within an organisation. In contrast to this basically harmonious picture of functional differentiation, Max Weber portrays the birth and composition of modern society as an emergence of a number of autonomous "value spheres". One after another, science, law, art, $(\leftarrow$ p. 2) politics, economics, sexuality and intimate relations, and other spheres of human activity freed themselves from their former domination by religious doctrines. These spheres became societal domains of their own which cultivate their particular central value without concern for the value orientations of other domains. Modern science, for instance, does not and should not care about economic profits, aesthetic beauty, legality, or the conformity of ist truths with religious doctrine. Weber (1919: 27/28) speaks graphically about the "polytheism" of "value spheres" in modern society.

Niklas Luhmann formulates this perspective on functional differentiation even more to the point. To him, modern society consists of about a dozen subsystems in each of which communications and activities are guided by a specific binary code. For instance, the science system's binary code is "true/untrue", the legal system's "legal/illegal". The binary code of each subsystem establishes a highly selective searchlight onto the social world, illuminating certain corners of it and leaving the rest in the dark. The overall result is an effective multiplication of society with regard to the social meanings of events. A train accident, for example, looks totally different from the point of view of the economy, compared to the point of view of science, compared to the point of view of the health care system, compared to the point of view of the mass media, and so on. Luhmann calls this the "polycontexturality" of modern society.

In this view of Weber and Luhmann, a subsystem's autonomy consists in the primacy of its own central value or binary code as the evaluative standard which guides all operations within the $(\leftarrow$ p. 3) subsystem. Autonomy, in this sense, does not go along with autarky. In an economic language, all subsystems need raw materials and other factors of production from other subsystems, and provide them, in turn, with certain goods and services. Despite these manifold "double interchanges", as Parsons 
calls them, or "structural couplings" - in Luhmann's terminology - the latter insists that a proper understanding of modern society must, first of all, recognize each subsystem's autonomy.

Let me now specify these general concepts for modern sport! It is one of the functionally differentiated societal subsystems. Its binary code is "win/lose". To win is ultimately "what it's all about" - the other way round, all kinds of sport activity boil down to the avoidance of losing. Considerations of winning or losing frame everything that is done and everything that is talked about within sport. Again, this does not mean that, for example, needing or making money, "making the news", promoting one's health or legal stipulations are irrelevant aspects of sport activities. But these are secondary determinants of action within sport in the sense that they just work as restrictions or opportunities, but do not define - in Pierre Bourdieu's (1992: 353-365) language - this subsystem's specific "nomos".

As should be clear by now, the theoretical perspective I have chosen ties analytically a societal subsystem's autonomy to its binary code. When it comes to deal with a subsystem's suspected autonomy trouble this theoretical strategy focusses attention on the relationship of the subsystem's code as the internal and primary , $(\leftarrow$ p. 4) determinant of action to secondary, external determinants. More precisely, how much or how little is the self-referential "nomos" of the subsystem embedded within other-referential orientations of action? Derived from similar reflections about several other societal subsystems, my intuitive heuristic idea is that a subsystem has to maintain a certain balance of self- and other-reference in its operations. Structurally, this means that neither the total disembeddedness of a subsystem from society, nor the subsystem's total embeddedness within society, is functional for the subsystem's reproduction.

Interestingly, the sport system gives us an opportunity to study both dysfunctional tendencies more concretely: one by looking at top athletics, the other by looking at leisure sport.

\section{Top Athletics: Dangerous Autonomy}

By top athletics I refer to those individual and corporate actors within sport which participate in national and, as a next step, international competitions, or at least aim to 
do so. In other words, this subsystem of modern sport makes up its part of the "world society" (Luhmann 1971). Indeed, sport is one of the subsystems of modern society which formulated quite early and very explicitly a program of global extension by the institutions of world records and world championships, especially the Olympic Games, for top athletics. As long as some record or championship is territorially restricted, the , $(\leftarrow$ p. 5) question remains whether the particular athlete or team is really the best one all over the world. In this sense, globalization is inherent to the "win/lose" code.

World-wide competition has certainly reinforced what Kalevi Heinilä (1982) calls the "totalization" of top athletics. But even more basic have been some "structural couplings" of the sport system with other societal subsystems. I do not have to go into details because the facts are familiar. Top athletics has institutionalised interchanges of mutual utility with the economy, the political system, and the mass media. Actors from all three societal subsystems - firms, politicians, the government, television stations and newspapers - profit in various respects from their involvement with top athlets as individuals, teams and sport organizations as corporate actors. The most important general gains which top athletics gets in return are money and public attention. In addition, top athletics is strongly linked to certain segments of the science system from which it is supplied with useful knowledge for the optimization of performance in many disciplines. Finally, one should not overlook the manifold contributions of the families of top athletes, ranging from logistic services to motivational help. And of course, there are certain returns to scientists and families from this involvement with top athletics, too.

All these and some other "double interchanges" have intensified significantly during the last decades. It is safe to say that, on the one hand, the "interpenetration" to use Richard Münch's (1980) terminology - of top athletics with its societal environment has increased. On the other hand, this structural dynamic has not led to a $(\leftarrow$ p. 6) decrease of autonomy of top athletics. How can that be, although top athletics has become more dependent upon the various inputs from these other subsystems? How does a higher dependency go along with the same or, I would even say, a higher autonomy of top athletics? A proper understanding of this curious interplay of dependency and autonomy is essential to grasp the latter's dangerousness.

The "totalization" of top athletics which results from its "interpenetration" with other societal subsystems refers to two kinds of growth: first, the enormous quantitative 
growth of the sport public and its interest in sport events worldwide, and secondly, the remarkable qualitative growth of the performance level and, moreover, the level of performance expectations in all sport disciplines. A reciprocal causality is at work. The growth of support from other subsystems - money, other kinds of resources, attention, knowledge etc. - has given the opportunity to top athletics to improve its performance and broaden its performance base: An increasing number of top athletes all over the world has become better and better, not the least driven by an increasing competition among them. This ongoing improvement of performance has attracted and kept a firm hold on a growing sport public: More and more people worldwide spend more and more time at sport events, either in the stadium or in front of their television at home. In turn, this growing public attention to top athletics has made it an even more attractive target for support from the economy, the political system, and the mass media because actors from these subsystems can hope for growing returns from $(\leftarrow \mathbf{p}$. 7) their investments. And so the spiral of quantitative and qualitative growth of top athletics has emerged, with no prospects for a stop.

Seen somewhat simplified as an inter-systemic constellation, this dynamic is produced by a bilateral monopoly among top athletics, on the one hand, and the mentioned other societal subsystems, on the other, mediated by the sport public. A significant number of actors from the mass media, the political system, and the economy cannot do without their involvement with actors from top athletics, and vice versa. Both sides are certainly not totally and forever, but strongly dependent upon what they get from the other side; and there are no ready alternative suppliers of the respective kinds of support. The mutuality of dependency prevents one-sided domination - in other words: protects and even expands the autonomy on both sides. Top athletics does not interfere with the logics of economic profit-making, political power-plays, and mass media's "newsworthiness", but fosters these logics by its own particular means, as far as they go. The other way round, these other logics, as well as those of science or family life, do not fight for supremacy with the "win/lose" code of top athletics within its jurisdiction but accept it - even more, support it because this is to their own advantage.

As a result, the intensification of "double interchanges" has disembedded the binary code of top athletics. What sounds paradoxical on first sight, is, I hope, quite logical now. To jump from this still abstract conclusion to a concrete manifestation, I propose - based on extensive studies done in collaboration with Karl-Heinrich $(\leftarrow \mathbf{p}$. 
8) Bette - that doping is an inevitable consequence of this growing "interpenetration" of top athletics with its societal environment (Bette/Schimank 1995). In a sense, one might say that doping shows nothing less than the true nature of top athletics. Obviously, this view runs counter to the usual reading of doping as deviant behavior of "weak" individuals. In acts of doping, the disembeddedness of an athlete's actions and biography from other considerations besides the concern for winning manifests itself. In the final end, nothing else counts as a relevant criterion for the decision to dope or not to dope but the calculation how much doping might help winning, and how probable it is that one is detected.

I cannot spell out here the biographical dynamics which lead an individual athlete into what Bette and I call the "doping trap". The point to underline is that it is much too simple to see doping as a consequence of a too high dependency of top athletics upon the economy, the political system, or the mass media. This view equates high dependency with low autonomy. For example, the growing "commercialization" of top athletics is pointed out as a tendency which erodes this subsystem's own evaluative standards. But the opposite is true, at least if one understands these standards not as a sentimental ideal of "true sportsmanship" but as an outline of a social character shaped by the "nomos" of modern sport. In this sense, the "doping trap" is a manifestation of the autonomy of top athletics - a dangerous autonomy, for individual athletes as well as for sport organizations. $(\leftarrow$ p. 9$)$

The dangers to athletes with respect to their bodily health as well as to their moral consciousness and their individual identity are well-known by now. But there are also dangers to sport organizations, and to top athletics in general. These dangers consist in a profound loss of legitimacy of top athletics in society. This may have two major consequences. First, support from the economy, the political system, and the mass media could fade away. Such a development would bring about an overall decline of top athletics, especially a decay of the performance level; and this could very well be a deadly danger to a societal subsystem which has institutionalized a permanent improvement of performance in all of its disciplines. A second consequence of de-legitimation by doping could be rigorous political and legal interventions. Political actors might come to the conclusion that they have to stand in where the sport organizations fail to act. Both consequences have in common that they strongly curtail the autonomy of top athletics by restricting the room to manoeuvre for activities 
oriented to the "win/lose" code, either by political and legal power or by lack of money; and both may happen simultaneously.

To be precise, none of these external influences abolishes the sovereign jurisdiction of the binary code of the sport system in decisions about who wins and who loses a competition. But the territory of this jurisdiction can be reduced by these influences - in the extreme to an altogether irrelevant autonomy. If the sport public turns away in large numbers because its expectations of an ever-increasing performance level are permanently disappointed as a $(\leftarrow$ p. 10$)$ result of the declining support of top athletics and increasing political interventions into it, this subsystem of the sport system becomes literally invisible within society. Nobody cares any longer what happens there; nobody tells what happens in top athletics; and sooner or later nobody knows that it exists at all. Eventually even political interventions would cease, and a state of total disembeddedness of top athletics in society would be reached. In this sense, doping could turn out to be the predetermined gravedigger of top athletics, as the structurally built-in result of its autonomy; and one can speak of a dangerous autonomy because doping leads to a self-marginalization of this subsystem of modern sport.

\section{Leisure Sport: Endangered Autonomy}

Turning now to leisure sport, attention is shifted to the other subsystem of modern sport which includes all kinds of sport activities that are not driven by an ambition to win in national or international competitions. To be successful in regional or local competitions is the highest aspiration level of leisure sport; the lowest one does not refer to any comparison with other athletes but only with oneself (Stichweh 1990) take as an example the jogger whose aim is to surpass her or his own previous performance, or, becoming older, to maintain a certain performance level as long as possible. To be sure, even in this case the "win/lose" code governs sport activities, and how someone talks and thinks about them. $(\leftarrow$ p. 11)

Historically, the emergence of the sport system in the early nineteenth century happened as a successive differentiation of leisure sport from several other already differentiated societal subsystems - especially the educational system, the military system, and the health care system (Schimank 1988; Cachay 1988). Thus, it 
was leisure sport, not top athletics, which initiated the differentiation of the sport system. The structural dynamic was the same in all three cases: The other subsystems "outsourced" some part of their societal functions; and these diverse functions amalgamated to a new societal subsystem. In the case of health care the respective functions were delegated to roles and organizations which exist outside this subsystem whereas in the case of education partly roles and organizational sub-units inside this subsystem, such as sport at schools, were used; the same is true for the military. But even when the functional "outsourcing" remained structurally within the respective subsystem, the decisive thing about it was that the diverse functions of sport activities for education, health care, the military and some other societal subsystems triggered and soon firmly rested on a common evaluative orientation: the binary code of "win/lose". Thus, it is by no means a historical necessity that sport emerged as a functionally differentiated subsystem of modern society. Instead, this was a "Cournot effect" (Boudon 1984: 173-179). It was chance that the different "outsourcings" firstly, coincided at about the same time and secondly, fitted together within the framework of the same binary code. $(\leftarrow$ p. 12$)$

The "win/lose" code could win supremacy because the functions of leisure sport to the other subsystems could only be fulfilled if those who engaged in sport activities were, above all other things, dedicated to compete with others and win these competitions. These functions are good examples of what Jon Elster (1983) calls "states that are essentially by-products". They are necessarily trans-intentional outcomes of action which is guided by a quite different intention. To be more concrete, take the educational functions of sport activities. It is supposed that participation in sport, whether at schools or in sport clubs, builds character in a number of important aspects, among them self-discipline, team-spirit, empathy, and the will to work hard. Obviously, neither children playing soccer nor adults who regularly attend a fitness studio do this to produce these effects. Even if they have in mind this educational value of their sport activities, this is a distanced self-reflection and not what they worry about when they actually do play soccer or lift weights. At that moment, all that counts in their immediate self-experience is whether they get the ball before the player from the other team, pass it to that player from their own team who is in a good position to kick a goal, and whether this is successful. Coupled with the bodily exertion, a strong emotional force commands athletes' minds. This brings about a "tunnel vision", as it is familiar from all kinds of emotions. In this sense, the "win/lose" code totally occupies the 
athlete's mind while he or she is engaged in the respective sport activity. No educational considerations are relevant at all, and the same is true for all other societal functions of modern sport. $(\leftarrow$ p. 13)

In this way, the sport system emerged as an evolutionary late-comer in modern society. The other subsystems had to exist already on highly developed levels of performance because the sport system's initial role in the ensemble of subsystems was the role of a dutiful servant to several of them. Despite this functional subordination modern sport soon reached the same kind of systemic autonomy as the other subsystems. This autonomy rests on three bases. First, a servant who has many masters can take advantage of this position by playing off one against the other. Conflicting demands from different subsystems can neutralize themselves mutually so that the sport system's autonomy is maintained. This "divide and conquer from below" can, to some extent, happen in an unintended way; skilled defenders of the autonomy of sport are able to make even greater intentional use of such a constellation. Second, the other subsystems soon became dependent upon a proper performance of the sport system. They deprived themselves of the capacity to produce the respective functions on their own. For instance, the longer the health care system became accustomed to the fact that regular sport activities prevent certain serious illnesses the less it could do without this support of its own operations. Third, as already mentioned a proper performance of the sport system necessitates the primacy of the "win/lose" orientation in all sport activities. This is the most important base of the autonomy of the sport system. The other societal subsystems would sabotage the satisfaction of their own needs if they did not grant this autonomy. $(\leftarrow$ p. 14)

Despite occasional violations the representatives of the relevant other subsystems are usually aware of their own best interests. They respect the autonomy of modern sport. Nevertheless, the autonomy of leisure sport is endangered from another direction. Not interferences from other subsystems but the "misbehavior" of the central actors of leisure sport increasingly endangers the autonomy of this subsystem of modern sport. To put it in a nutshell, it is exactly the overwhelming success of leisure sport in the recruitment of more and more persons as active participants which may become a serious problem to its autonomy (Schimank 1992).

This paradoxical assessment of "successful failure" becomes understandable if one takes a closer look at the motivations of many of those who have become included 
into leisure sport in the past decades. Until the beginning of the ' 60 s a strong majority of those who engaged in leisure sport identified themselves with the competitive orientation that fits to the "win/lose" code. Although they had no ambitions of national or even international excellence, their much more modest ambitions in doing sport were basically of the same kind and as pure as the ambitions of top athletes: to win in competitions, and nothing else. The only difference between both actors was that for top athletes success in sport was the center of their life whereas athletes in leisure sport had other biographical priorities - for adult males usually their work, for adult females their family. In this respect, there was no principal difference between top athletics and leisure sport, just a gradual one. $(\leftarrow$ p. 15)

As Ilse Hartmann-Tews (1996) shows in her detailed comparative study of the development of leisure sport in Germany, Great Britain, and France, since then a deliberate policy of "sport for everybody" has been implemented - most effective in Germany, but significant also in the other two countries, and elsewhere in Europe and the Western World. This quantitative growth of leisure sport has led to an inclusion of more and more persons with heterogeneous "watered-down" motivations, measured by the competitive orientation of traditional leisure sport. Of course, traditionally not only in Germany there have been the gymnasts who never adhered to the "win/lose" code but practiced their exercises primarily for health reasons. However, gymnasts were seen, and saw themselves, as a special group within leisure sport. Now, their indifference to the constitutive orientation of the sport system began to spread among many of those who were newly recruited into this subsystem of modern sport. By far the most powerful motivation that began to supersede the competitive orientation was to practice sport in order to maintain or restore one's health. Other such motives referred to opportunities for socializing which are offered by leisure sport, or new kinds of bodily experiences and thrills which can be made.

All subsystems of modern society subject newly recruited persons to some process of socialization. Especially the primacy of the respective subsystem's binary code must be imprinted into their understanding of the roles they are playing within the subsystem. In most cases, however, there is an asymmetric relationship between individual persons seeking some kind of inclusion into a particular $(\leftarrow$ p. 16) subsystem, or even being included by force as with children into the educational system, on the one hand, and the subsystem granting and defining the conditions of inclusion, on the other. The individuals are clearly the weaker side of the relation. In 
contrast, inclusion into leisure sport is - in an economic analogy - not a sellers' but a buyers' market. The reason for this is simply that an engagement in sport is no existential necessity for an individual. With respect to such necessities, a person has to accept to a high degreee the terms of trade the respective subsystem lays down, as with patients in the health care system or consumers in the economy. Practicing sport is something a person can do without; there are still many who are totally passive in this respect, sometimes for all of their lives. Thus, leisure sport has to adapt to the motivations of those who are potentially interested in it to attract and keep them as members of sport clubs or fitness studios, or as regularly practicing individual athletes. And this adaptation does not just consist in picking people up where they are and leading them gradually to "true sportsmanship" but in giving up any hopes of such resocialization and instead "giving the people what they want" on a permanent basis. This is the price to pay for the enormous growth in numbers of persons engaged in sport.

I cannot dwell here on the manifold empirical phenomena which exemplify such a structural dynamic of leisure sport, nor can I comment on the debates among representatives of sport clubs and sport associations about these at first unnoticed side-effects of their, in most cases quite willing, pursuit of the "sport for all" policy. Again, I $(\leftarrow$ p. 17) am sure you know what I refer to. Here it suffices to note that leisure sport confronts the sport system with a dilemma of inclusion. The growth of members has meant additional financial resources as well as an increase of societal standing of sport clubs and associations. Those tendencies and policies which have improved the resource base of the sport system and extended its importance to society endanger its autonomy because the "win/lose" code might become more and more marginalized within leisure sport. It may be not too far-fetched to anticipate a de-differentiation of leisure sport. Part of it could become a subordinated segment of the health care system; another part might become a segment of leisure industry; sport at schools might become dominated again by pedagogical requirements and principles, likewise sport in the military by this subsystem's needs; and so on ... In a sense, history would go backward because leisure sport would disintegrate into more or less the same fragmented parts out of which it emerged in the nineteenth century. To be sure, the other subsystems would realize at some point that these parts do no longer deliver what they got from an autonomous leisure sport. When "the states that are essentially by-products" are pursued intentionally the vital emotional driving-force is lacking, and 
soon the motor runs dry. But the moment when this will become apparent might be too late to reanimate leisure sport.

\section{Mutual Dependence of Top Athletics and Leisure Sport $(\leftarrow$ p. 18)}

The results of my separated discussions of the autonomy problems of the two subsystems of modern sport are very different, but represent both highly critical prospects. The dynamics of top athletics go into the direction of a rigorous orientation to the "win/lose" code, and this development unleashes the dangerous potential of the autonomy of sport. In contrast, the dynamics of leisure sport erode this code and in this way endanger the autonomy of sport. Top athletics is too much disembedded from its societal environment, while leisure sport is too much embedded within it. The two corresponding fates are that society forgets about top athletics, and those engaged in leisure sport forget about the true meaning of sport. Both are vital dangers to the sport system.

Although both dynamics are built into the basic structures of modern sport, they are not inevitable, and many actors within the sport system make an effort to correct them. I cannot take stock and evaluate all the different strategies which are tried out in both respects. Obviously, in most cases what might help against a dangerous autonomy does not help an endangered autonomy, and vice versa. Still, there is a vital connection between these two arenas of coping. Success in both arenas, if it is possible at all, relies on a mutually legitimating "double interchange" between top athletics and leisure sport.

In one direction, top athletics legitimates itself by the fiction of being just an especially elitist variant of leisure sport. As I understand it here, a fiction is an account of reality which is neither literally true nor simply false but something "in-between". Scientific models, such $(\leftarrow$ p. 19) as the homo oeconomicus of rational choice theories, are cognitive fictions. We can use this model for explanatory purposes, but we must be aware of its limits. Seeing itself as "basically the same" as leisure sport is a normative fiction of top athletics. This fiction is an attempt to counterbalance the "totalization" of top athletics by keeping alive an understanding of all sport as the "most delightful secondary matter of the world" ("schönste Nebensache der Welt"), to adopt a famous saying from a former representative of German sport associations. This spirit 
is obviously not the one that governs top athletics; but to keep it in mind by emphasizing the oneness of both subsystems of modern sport could help to qualify at least a little bit the competitive orientation, and the inclination to doping as its consequence within top athletics. And even if there should be no effect of this normative fiction with respect to "action", it is nevertheless useful in the dimension of "talk", to use Nils Brunsson's (1989) distinction. It is easier to pretend that top athletics has no doping problem if one presents it as "basically the same" as leisure sport.

In the other direction, leisure sport needs the good example of top athletics to keep alive the "win/lose" code against the flood of other-referential orientations. There is another normative fiction at work here. Those active in leisure sport should practice it as if they were top athletes to whom winning competitions is the most important thing in life. Again, everybody knows that persons who are engaged in leisure sport have other priorities for their life. But in order to take their competitions sufficiently seriously with regard to winning, $(\leftarrow$ p. 20) they are reminded that they do "basically the same" as top athletes. Again, this fiction may help in the dimension of "action", on the one hand. Perhaps some of those who start practicing leisure sport for nothing but health reasons become fascinated by the competitive orientation when they run the Cologne marathon together with famous top athletes. On the other hand, the fiction is effective in "talk". It is one means to defend leisure sport against its disintegration into subordinated parts of other societal subsystems.

As a consequence, no institutional or cultural separation of both subsystems of modern sport is feasible. United they might have a chance to stand, divided they will surely fall as an autonomous subsystem of modern society. Nobody knows what fate awaits the sport system in the coming decades. But to know the dangers is the best we can do to prevent the worst to happen. $(\leftarrow$ p. 21)

\section{Literature}

Bette, Karl-Heinrich/Uwe Schimank, 1995: Doping im Hochleistungssport. Frankfurt/M.: Suhrkamp. 
Boudon, Raymond, 1984: Theories of Social Change. A Critical Appraisal. Oxford, 1986: Polity Press.

Bourdieu, Pierre, 1992: Die Regeln der Kunst. Frankfurt/M. 1999: Suhrkamp.

Cachay, Klaus, 1988: Sport und Gesellschaft. Schorndorf: Hofmann.

Hartmann-Tews, Ilse, 1996: Sport für alle!? Strukturwandel europäischer Sportsysteme im Vergleich: Bundesrepublik Deutschland, Frankreich, Großbritannien. Schorndorf: Hofmann.

Heinilä, Kalevi, 1982: The Totalization Process in International Sport. In: Sportwissenschaft 12, 235-252.

Luhmann, Niklas, 1971: Die Weltgesellschaft. In: Niklas Luhmann: Soziologische Aufklärung, Bd. 2: Aufsätze zur Theorie der Gesellschaft. Opladen, 1975: Westdeutscher Verlag, 51-71.

Münch, Richard, 1980: Über Parsons zu Weber: Von der Theorie der Rationalisierung zur Theorie der Interpenetration. In: Zeitschrift für Soziologie 9, 18-53.

Schimank, Uwe, 1988: Die Entwicklung des Sports zum gesellschaftlichen Tellsystem. In: Renate Mayntz u. a., Differenzierung und Verselbständligung. Zur Entwicklung gesellschaftlicher Tellsysteme. Frankfurt a. M.: Campus, 181-232. 
Schimank, Uwe, 1992: Das Inklusionsdilemma des Breitensports. In: Sportwissenschaft 22, 32-45.

Schimank, Uwe, 1996: Theorien gesellschaftlicher Differenzierung. Opladen: Leske + Budrich.

Schimank, Uwe, 2002: Differentiation, Social. In: Neil J. Smelser/Paul Baltes (eds.), International Encyclopedia of the Social and Behavioral Sciences. Oxford 2002: Pergamon, 3663-3668.

Stichweh, Rudolf, 1990: Sport - Ausdifferenzierung, Funktion, Code. In: Sportwissenschaft 20, 373-389.

Thompson, James D., 1967: Organizations in Action. New York: Mc Graw Hill.

Weber, Max, 1919: Wissenschaft als Beruf. Berlin 1967: Duncker \& Humblot. 
Uwe Schimank

The autonomy of modern sport: endangered and dangerous

\section{Abstract}

From the point of view of sociological theories of societal differentiation, modern sport is one of about a dozen differentiated sub-systems of modern society. This analytical perspective raises the question of the systemic autonomy of modern sport. This question shall be dealt with by distinguishing further the two differentiated secondorder sub-systems of sport: top athletics and leisure sport. Whereas for top athletics a dangerous autonomy - in the final end, dangerous to itself - can be diagnosed, leisure sport is characterized by an endangered autonomy. Interestingly, coping with these two very different problems of sub-systemic autonomy relies on a mutually legitimating double interchange among top athletics and popular sports. Thus, both sub-systems of modern sport cannot exist without and separated from each other.

Keywords:

top athletics, leisure sport, societal differentiation, sub-systemic autonomy

\section{Biographical note}

Born 1955, study of sociology in Bielefeld, researcher at the Cologne Max-PlanckInstitut für Gesellschaftsforschung, since 1996 professor of sociology at the FernUniversität in Hagen. 